\title{
Atrial natriuretic peptide and feeding activity patterns in rats
}

M.H.A. Oliveira ${ }^{1}$, J. Antunes-Rodrigues ${ }^{3}$, J. Gutkowska², A.M.O. Leal ${ }^{4}$, L.L.K. Elias ${ }^{4}$ and A.C. Moreira ${ }^{4}$

\author{
${ }^{1}$ Departamento de Medicina, Universidade Federal de Sergipe, 49060-100 \\ Aracaju, SE, Brasil \\ ${ }^{2}$ Centre de Recherche Hôtel-Dieu de Montreal, Pavilion Marie-de-la-Ferre, \\ Montréal, Quèbec, H2W 1T8, Canada \\ Departamentos de ${ }^{3}$ Fisiologia and ${ }^{4}$ Clínica Médica, \\ Faculdade de Medicina de Ribeirão Preto, Universidade de São Paulo, \\ 14048-900 Ribeirão Preto, SP, Brasil
}

\section{Correspondence \\ A.C. Moreira \\ Departamento de Clínica Médica \\ Faculdade de Medicina de \\ Ribeirão Preto, USP \\ 14048-900 Ribeirão Preto, SP \\ Brasil \\ Fax: 55 (016) 633-1144 \\ Presented at the International \\ Symposium "Neuroendocrine \\ Control of Body Fluid Homeostasis", Ribeirão Preto, SP, Brasil, \\ August 17-20, 1996. \\ Research supported by CNPq and HCFMRP-FAEPA. Publication supported by FAPESP.}

Received November 29, 1996 Accepted January 6, 1997

\section{Abstract}

This review presents historical data about atrial natriuretic peptide (ANP) from its discovery as an atrial natriuretic factor (ANF) to its role as an atrial natriuretic hormone (ANH). As a hormone, ANP can interact with the hypothalamic-pituitary-adrenal axis (HPA-A) and is related to feeding activity patterns in the rat. Food restriction proved to be an interesting model to investigate this relationship. The role of Key words - Atrial natriuretic peptide - Corticosterone

- ACTH

- Food restriction

\section{A factor, at the beginning}

The discovery of a natriuretic factor from cardiac atria $(1,2)$ led to further characterization of a complex natriuretic hormonal system, including a 126-amino acid prohormone synthesized within myocytes of the heart and stored in granules for release into the circulation. This hormonal system includes several peptides such as the prohormone proatrial natriuretic factor (ANF) 1-30, a longacting sodium stimulator, pro-ANF 31-67, a vasodilator, pro-ANF 79-98, a kaliuretic stimulator, and pro-ANF 99-126. Each of these peptides has blood pressure-lowering, diuretic, natriuretic, and/or kaliuretic properties in both humans and animals. When released into the circulation, these peptides circulate as a 28 -amino acid C-terminus (i.e, ANF) of this prohormone and as a 98-amino acid N-terminus which is proteolytically cleaved into pro-atrial natriuretic peptide (ANP) 31-67 and pro-ANF 1-30. The peptides enhance the particulate form of the enzyme guanylate cyclase increasing the intracellular messenger cGMP that has been shown to be the final mediator of the observed vasodilatation and natriuresis secondary to atrial natriuretic peptides $(3,4)$. A single ANF gene has been identified in all mammalian species examined to date. In man this gene is located on chromosome 1, band $\mathrm{p} 36$, and is one of a syntenic group that is present on chromosome 4 of the mouse. The gene consists of three exons separated by two introns. More recently, brain natriuretic peptide (BNP) and C-type natriuretic peptide (CNP) and at least three subtypes of receptors were identified (5). In this review we will use the name ANP although the term atrial natriuretic hormone (ANH) would be more appropriate. 


\section{Atrial, but not only atrial}

ANP has been identified in many different tissues and may have several important physiological functions other than natriuresis and vasodilation. In brain it exists as amino-terminally truncated form. Two systems are involved in the secretion of ANP: peripheral ANP (heart and plasma) and central ANP (paraventricular, periventricular, arcuate, and pre-optical-medial nuclei and other sites) (6). Despite the blood-brain barrier, these systems communicate through the circumventricular organs, the organum vasculosum lamina terminalis and the organum subfornicalis (7-9). They are connected by neuronal synapses (9-14), or by discharge of peptides such as vasopressin (15), endothelin (11) and oxytocin (16) from the hypothalamus. Therefore, ANP may participate in the control of different functions such as the reduction of the activity of the renin-angiotensin-aldosterone system and inhibition of salt and water intake in the rat $(17,18)$. Nevertheless, ANP originating from the paraventricular nucleus (PVN) is responsible for 87 to $92 \%$ of the content of ANP in the median eminence and is involved in the regulation of the function of the anterior pituitary (19). Several experiments using immunoneutralization techniques have demonstrated that ANP, in addition to participating in the control of LH and prolactin secretion $(20,21)$, may be a factor inhibiting corticotropin release (21-24).

\section{Natriuretic, but where?}

ANP was discovered on the basis of its pharmacological properties of producing diuresis and natriuresis, although at the periphery its vasodilating action is probably more important. Transgenic mice with ANP levels 2- to 10-fold the normal values exhibit essentially normal fluid and electrolyte homeostasis, a fact that argues against a fundamental role of peripheral ANP in water and sodium metabolism. However, the mice with the highest ANP levels were significantly hypotensive indicating that these pharmacologic renal effects of the peptide are less important than its hemodynamic actions (4). On the other hand, in rats or in humans, high ANP concentrations are hypotensive even when they are lower than natural concentrations in the pituitary portal system, and are able to inhibit ACTH secretion in vitro (25). Nevertheless, under appropriate conditions, the antagonism between the natriuretic peptide system and the renin-angiotensin system can promote natriuresis. For instance, ANP inhibition of stress-induced vasopressin release may increase renal water loss and the diminished ACTH release induced by ANP may lead to a reduction in aldosterone secretion, thereby diminishing the stress-induced sodium retention (26), a mechanism demonstrating the central natriuretic action of ANP.

\section{And what else? ANP and the HPA-A}

Two lines of research have been exhaustively followed by our group since the early eighties. First, the investigation involved the brain ANPergic neuron system and its role as antagonist of the renin-angiotensin system, its influence on ANP release including ANP release induced by volume expansion (914,17-18), and other hormonal effects of the brain ANP system on $\mathrm{LH}$, prolactin, GH, TSH, and ACTH secretion (20,24). In parallel, we investigated the circadian rhythmicity of the hypothalamic-pituitary-adrenal axis (HPA-A) in rats with continuous or restricted access to food (27). It is well known that rats manifest a circadian peak of plasma corticosterone and ACTH just before the onset of predominant food intake (28). We demonstrated for the first time circadian and parallel ANP and corticosterone variations in rats with continuous (peak at 20:00 h) or restricted access to food from 9:00 to 11:00 $\mathrm{h}$, with a peak at 8:00 h (29). Both lines of 
investigation led to a better understanding of the relationship between brain and peripheral ANP involving neuronal and peptidergic interactions. The activation of the central noradrenergic pathway is involved in the volume expansion-induced ANP release and the circadian variation of corticosterone and ANP in rats. High levels of noradrenaline and elevated numbers of alpha-2-adrenoreceptors are found in PVN (30), producing a large burst of food intake and activity at the beginning of the dark period simultaneously with an increase of cardiac rate and pressure (31). In addition, the central noradrenergic pathway is activated before feeding time in food-restricted rats. Food restriction induces a disruption of activity-rest and sleep-wake patterns with changes in the hippocampal content of norepinephrine and serotonin, and in the cortical content of serotonin (32), and corticotropin-releasing hormone ( $\mathrm{CRH})$-related neurotransmitters involved in feeding behavior (33). Feeding patterns result from a complex balance between anorectic ( $\mathrm{CRH}$, cholecystokinin (CCK), neurotensin) and orectic (neuropeptide Y (NPY), pancreatic polypeptide, galanine) factors, constituting a complex circuitry. CRH and NPY deserve additional comments. Food restriction induces an increase of NPY mRNA level in the arcuate nucleus and reduces the CRH mRNA level in PVN in a physiological response to restore food intake (34). Dallman et al. (35) suggested that the NPYergic system, the activity of which is increased by fasting and reduced by feeding, by insulin and lack of glucocorticoids, may mediate the fastinginduced override of diurnal rhythms in the HPA-A. We propose that the food-restricted high corticosterone levels may contribute to the observed reduction of CRH mRNA through an action of ANP. In addition, glucocorticoids areable to stimulate ANP secretion or genic activity (36-41). This effect may be consistent with a possible hypothalamic-cardio-adrenal feedback control mechanism (29).

\section{Diurnal ANP variations and food restriction}

Because rats drink when they eat and eat when they drink, restriction of water or food effectively restricts consumption of both (35). To test the hypothesis of food restriction being a paramount "zeitgeber" for the diurnal variation of corticosterone, ACTH and ANP and to determine the role of water restriction, we studied these rhythms in water-restricted rats (water from 9:00-11:00 h). Water-restricted rats showed a double corticosterone peak at 8:00 and 20:00 $\mathrm{h}$ and an ACTH peak at 8:00 h, and did not show diurnal variation of ANP. We concluded that food intake is a more important synchronizer than water intake for the activity and HPA rhythmicity. We believe that the effects of water restriction on corticosterone and $\mathrm{ACTH}$ secretion are mediated by changes in food intake since there is a spontaneous burst of feeding in the presence of a water supply. Water-restricted rats are less active during the light period than food-restricted rats. In fact, food-restricted rats with exclusive $0.9 \%$ or $1.5 \% \mathrm{NaCl}$ intake exhibit more hyperactivity and more intense drink-seeking behavior, thereby abolishing the diurnal circadian variation in ANP due to a high ANP secretion during this period. Free fed adrenalectomized rats showed no diurnal ANP variation. This may be attributed to a reduction of the spontaneous food intake and activity during the dark period in comparison to the light period, due to a reduction in the alpha-2adrenoreceptors in PVN, as shown by Bhakthavatsalam and Leibowitz (42) and Jhanwar-Uniyal et al. (30). We do not know whether a stimulating effect of glucocorticoids on the genic transcription of ANP contributes to the evening ANP peak and is eventually suppressed by adrenalectomy (ADX). We demonstrated that dexamethasone $(50 \mu \mathrm{g} / \mathrm{kg}$ body weight) administered intraperitoneally to $\mathrm{ADX}$ rats produced a drastic reduction of ACTH accompanied by 
a pronounced ANP increase within $90 \mathrm{~min}$. This result suggests that a simultaneous increase in portal ANP content may mediate the reduction of ACTH hypersecretion in ADX rats. It is interesting that this feedback mechanism uses the same type II receptor that mediates the high food intake occurring at the onset of darkness, which is abolished by ADX and restored by corticosterone (43).

\section{ANP, a feeding-related peptide? Peripheral or central actions?}

The interaction between insulin and corticosteroid serves as a peripheral hormonal feedback loop that regulates the well-known NPYergic feeding and fasting system, but if plasma insulin levels were elevated in an attempt to increase CNS insulin levels (in the hope of observing a consequent decrease in food intake) the resulting hypoglycemia would elicit an emergency increase in food intake (44). Similarly, if plasma ANP levels were increased to the high levels needed to inhibit the HPA-A, the resulting hypotension could have a stimulatory effect. Therefore, central ANP sites (PVN, arcuate nucleus, perifornical lateral hypothalamus, AV3V, subfornical organ, supraoptic nucleus) may act as integrating sites of a complex system that couples feeding, HPAA, physical activities and cardiovascular status. Corticosteroids and insulin may act as peripheral signals, and the locus ceruleus, nucleus tractus solitarius and dorsomedial nucleus as intermediate stations. The activation of noradrenergic and serotonergic pathways may be involved, but the nature of other interactions and peptides deserves further study.

\section{Acknowledgments}

The authors thank Miss Ana Cristina C. Pereira and Mr. Alex A. da Silva for secretarial assistance.

\section{References}

1. De Bold AJ, Borenstein HB, Yerss AT \& Sonnenberg H (1981). A rapid and potent natriuretic response to the intravenous injection of atrial myocardial extract in rats. Life Sciences, 28: 89-94.

2. De Bold AJ (1985). Atrial natriuretic factor. A hormone produced by the heart. Science, 230: 767-770

3. Vesely DL, Douglass MA, Dietz JR, Giordano AT, McCormick MT, RodriguesPaz G \& Schocken DD (1994). Negative feedback of atrial natriuretic peptides. Journal of Clinical Endocrinology and Metabolism, 78: 1128-1134.

4. Rosenzweig A \& Seidman CE (1991). Atrial natriuretic factor and related peptide hormones. Annual Review of Biochemistry, 60: 229-255

5. Imura H, Nakao K \& Itoh H (1992). The natriuretic peptide system in the brain: implications in the central control of cardiovascular and neuroendocrine functions. Frontiers in Neuroendocrinology, 13: 217-249

6. Ma LY, Zhang ML, Yang XD, Tian DR, Qi JS \& Zhang DM (1991). Neuroendocrinology of atrial natriuretic polypeptide in the brain. Neuroendocrinology, 53: 12-17.
7. Phillips $\mathrm{MI}$, Kimura $\mathrm{B}$, Wang $\mathrm{H}$ \& Hoffman WE (1989). Effect of vagotomy on brain and plasma atrial natriuretic peptide during hemorrhage. American Journal of Physiology, 257: 1393-1399.

8. Bahner U, Geiger H, Palkovits M, Gantem D, Michel J \& Heidland A (1990). Atrial natriuretic peptides in brain nuclei of rats with inherited diabetes insipidus (Brattleboro rats). Neuroendocrinology, 51: 721727.

9. Antunes-Rodrigues J, Ramalho MJ, Reis LC, Menani JV \& Turrin MQA (1991). Lesions of the hypothalamus and pituitary inhibit volume-expansion-induced release of atrial natriuretic peptide. Proceedings of the National Academy of Sciences, USA, 88: 2956-2960

10. Antunes-Rodrigues J, Machado $\mathrm{BH}$, Andrade HA, Mauad H, Ramalho MJ, Reis LC, Silva-Netto CR, Favaretto ALV, Gutkowska J \& McCann SM (1992). Carotid-aortic and renal baroreceptors mediate the atrial natriuretic peptide release induced by blood volume expansion. Proceedings of the National Academy of Sciences, USA, 89: 6828-6831.
11. Antunes-Rodrigues J, Marubayashi U Favaretto ALV \& Gutkowska J (1993). Essential role of hypothalamic muscarinic and alpha-adrenergic receptors in atrial natriuretic peptide release induced by blood volume expansion. Proceedings of the $\mathrm{Na}$ tional Academy of Sciences, USA, 90: 10240-10244.

12. Antunes-Rodrigues J, Picanço-Diniz WL Favaretto ALV, Gutkowska J \& McCann SM (1993). Brain atrial natriuretic peptide neurons play an essential role in volume expansion-induced release of atrial natriuretic peptide and natriuresis. Neuroendocrinology, 58: 696-700.

13. Antunes-Rodrigues J, Ramalho MJ, Reis LC, Picanço-Diniz DWL, Favaretto ALV, Gutkowska J \& McCann SM (1993). The possible role of endothelin acting within the hypothalamus to induce the release of atrial natriuretic peptide and natriuresis. Neuroendocrinology, 58: 701-708.

14. Reis LC, Ramalho MJ, Favaretto $A L$, Gutkowska J, McCann SM \& AntunesRodrigues J (1994). Participation of the ascending serotonergic system in the stimulation of atrial natriuretic peptide release. Proceedings of the National Academy of Sciences, USA, 91: 12022-12026. 
15. Manning PT, Scwartz D, Katsube NC, Holmberg SW \& Needleman P (1985). Vasopressin-stimulated release of atriopeptin: endocrine antagonists in fluid homeostasis. Science, 229: 395-397.

16. Haanwinckel MA, Elias LK, Favaretto ALV, Gutkowska J, McCann SM \& AntunesRodrigues J (1995). Oxytocin mediates atrial natriuretic peptide release and natriuresis after volume expansion in the rat. Proceedings of the National Academy of Sciences, USA, 92: 7902-7906.

17. Antunes-Rodrigues J, McCann SM \& Samson WK (1986). Central administration of atrial natriuretic factor inhibits saline preference in the rat. Endocrinology, 118: 1726-1728.

18. Baldissera S, Menani JV, Sotero S, Favaretto ALV, Gutkowska J, Turrin MQA, McCann SM \& Antunes-Rodrigues $J$ (1989). Role of the hypothalamus in the control of atrial natriuretic peptide release. Proceedings of the National Academy of Sciences, USA, 86: 9621-9625.

19. Palkovits M, Eskay RL \& Antoni FA (1987). Atrial natriuretic peptide in the median eminence is of paraventricular nucleus origin. Neuroendocrinology, 46: 542-544

20. Franci CR, Anselmo-Franci JA \& McCann SM (1990). Opposite effects of central immunoneutralization of angiotensin II or atrial natriuretic peptide on luteinizing hormone release in ovariectomized rats. Neuroendocrinology, 51: 683-687.

21. Fink G, Dow RC, Casley D, Johnston $\mathrm{Cl}$, Lim AT, Copolov DL, Bennie J, Carroll S \& Dick $H$ (1991). Atrial natriuretic peptide is a physiological inhibitor of $\mathrm{ACTH}$ release: evidence from immunoneutralization in vivo. Journal of Endocrinology, 131: 9-12.

22. Antoni FA, Hunter EFM, Lowry PJ, Noble JM \& Seckl JR (1992). Atriopeptin: an endogenous corticotropin-release inhibiting hormone. Endocrinology, 130: 17531755.

23. Fink G, Dow RC, Casley D, Johnston $\mathrm{Cl}$, Bennie J, Carroll S \& Dick H (1992). Atrial natriuretic peptide is involved in the ACTH response to stress and glucocorticoid negative feedback in the rat. Journal of Endocrinology, 135: 37-43.

24. Franci CR, Anselmo-Franci JA \& McCann SM (1992). The role of endogenous atrial natriuretic peptide in resting and stressinduced release of corticotropin, prolactin, growth hormone, and thyroid-stimulating hormone. Proceedings of the National Academy of Sciences, USA, 89: 11391-11395.
25. Lim AT, Shewardt WJ, Copolov D, Windmill D \& Fink G (1990). Atrial natriuretic factor is released into hypophysial portal blood: direct evidence that atrial natriuretic factor may be a neurohormone involved in hypothalamic pituitary control. Journal of Neuroendocrinology, 2: 15-17.

26. McCann SM, Gutkowska J, Franci CR, Favaretto ALV \& Antunes-Rodrigues J (1994). Hypothalamic control of water and salt intake and excretion. Brazilian Journal of Medical and Biological Research, 27: 865-884.

27. Moreira AC \& Krieger DT (1982). The effects of subdiaphragmatic vagotomy on circadian corticosterone rhythmicity in rats with continuous or restricted food access. Physiology and Behavior, 28: 787-790.

28. Krieger DT (1979). Rhythms in CRF, ACTH and Corticosteroids. Raven Press, New York, 123-142.

29. Oliveira MHA, Antunes-Rodrigues J, Leal AMO, Elias LLK \& Moreira AC (1993). Circadian variations of plasma atrial natriuretic peptide and corticosterone in rats with continuous or restricted access to food. Life Sciences, 53: 1795-1801.

30. Jhanwar-Uniyal M, Roland CR \& Leibowitz SF (1986). Diurnal rhythm of alpha-2-noradrenergic receptors in the paraventricular nucleus and other brain areas: relation to circulating corticosterone and feeding behavior. Life Sciences, 38: 473-482.

31. Jansen BJA, Tyssen CM, Duindam $H$ \& Rietveld WJ (1994). Suprachiasmatic lesions eliminate 24-h blood pressure variability in rats. Physiology and Behavior, 55: 302-311.

32. Krieger DT (1974). Food and water restriction shifts corticosterone, temperature, activity and brain amine periodicity. Endocrinology, 95: 1195-1201.

33. Beck B (1992). Cholécystokinine, neurotensine et corticotropin-releasing factor, trois importants peptides anorexigènes. Annales d'Endocrinologie, 53: 44-56.

34. Brady LS, Smith MA, Gold PW \& Herkenham M (1990). Altered expression of hypothalamic neuropeptide mRNAs in food-restricted and food-deprived rats. Neuroendocrinology, 52: 441-447.

35. Dallman MF, Strack AM, Akana SF, Bradbury MJ, Hanson ES, Scribner KA \& Smith M (1993). Feast and famine: critical role of glucocorticoids with insulin in daily energy flow. Frontiers in Neuroendocrinology, 5: 315-321.
36. Gardner DG, Hane S, Trachewsky D, Schenk D \& Baxter JD (1986). Atrial natriuretic peptide mRNA is regulated by glucocorticoids in vivo. Biochemical and Biophysical Research Communications, 139: 1047-1054.

37. Shields PP, Dixon JE \& Glembotski CC (1988). The secretion of atrial natriuretic factor (99-126) by cultured cardiac myocytes is regulated by glucocorticoids. Journal of Biological Chemistry, 263: 12619-12628.

38. Huang W, Choi GL, Yang Z, Copolov DL \& Lim AT (1991). Plasticity of adrenoceptor responsiveness on irANP secretion and pro-ANP mRNA expression in hypothalamic neuron cultures: modulation by dexamethasone. Endocrinology, 128: 2591-2600.

39. Weidmann $P$, Matter DR, Matter EE, Gnadinger MP, Uehlinger DE, Shaw S \& Hess C (1988). Glucocorticoid and mineralocorticoid stimulation of atrial natriuretic peptide release in man. Journal of Clinical Endocrinology and Metabolism, 66: 1233-1239.

40. Saxenhofer $H$, Angst $M$, Weidmann $P$, Shaw SG \& Ferrier C (1988). Corticosteroid-induced stimulation of atrial natriuretic peptide in man. Acta Endocrinologica, 118: $179-186$

41. Garcia R, Debinski W, Gutkowska J, Kuchel O, Thibault G, Genest J \& Cantin $M$ (1985). Gluco- and mineralocorticoids may regulate the natriuretic effect and the synthesis and release of atrial natriuretic factor by the rat atria in vivo. Biochemical and Biophysical Research Communications, 131: 806-814.

42. Bhakthavatsalam P \& Leibowitz SF (1986). Alpha-2 noradrenergic feeding rhythm in paraventricular nucleus: relation to corticosterone. American Journal of Physiology, 250: 83-88

43. Tempel LD, Yamamoto $M, \operatorname{Kim} T$ \& Leibowitz SF (1991). Effects of adrenalectomy on macronutrient selection patterns in the rat. Pharmacology, Biochemistry and Behavior, 40: 861-866

44. Schwartz MW, Figlewicz DP, Baskin DG Woods SC \& Porte D (1992). Insulin in the brain: a hormonal regulator of energy balance. Endocrine Reviews, 13: 387-414. 